\title{
Alat Pengeringan Cengkeh Otomatis Menggunakan Logika Fuzzy
}

\author{
Nadia Alfitri ${ }^{1}$, Amril $^{2}$, Reno Fajar Sidiq ${ }^{3}$ \\ ${ }^{123}$ Jurusan Teknik Elektro Politeknik Negeri Padang \\ nadianalfitri@pnp.ac.id
}

\begin{abstract}
Clove is one of the spices used as raw material for the industries of cigarettes, pharmaceuticals, cosmetics and spices in food ingredients. During the rainy season, dry clove production decreases, because farmers have difficulty in drying their clove crops. The purpose of this oven is to replace the role of natural drying by using an artificial machine and optimize the time and do not require extensive land for the drying process. This oven uses an automatic system to control temperature conditions in the drying box (oven) with the fuzzy logic algorithm method. For optimal drying the temperature used is between 440C to $470 \mathrm{C}$ with $450 \mathrm{C}$ set point. To get the same results with traditional drying, the time needed for clove drying tools is \pm 7 hours non-stop. The use of fuzzy logic algorithms that are applied to the device, can maintain the normal temperature conditions that we want with the speed of the motor exhaust fan according to decrease and increase in temperature. So that oven can dry the cloves optimally.
\end{abstract}

Keywords: clove, oven, fuzzy logic.

\begin{abstract}
Abstrak - Cengkeh merupakan salah satu rempah yang digunakan sebagai bahan baku industri rokok, farmasi, kosmetik dan rempah-rempah bahan makanan. Saat musim hujan, produksi cengkeh kering menurun, karena petani mengalami kesulitan dalam mengeringkan hasil panen cengkeh mereka. Tujuan dari pembuatan alat ini adalah menggantikan peran pengeringan secara alami dengan menggunakan mesin buatan dan mengoptimalkan waktu serta tidak memerlukan lahan yang luas untuk proses pengeringan. Pembuatan alat menggunakan sistem otomatis untuk megendalikan kondisi suhu di dalam box pengering dengan metode algoritma fuzzy logic. Untuk pengeringan yang optimal suhu yang digunakan yaitu antara $44^{\circ} \mathrm{C}$ sampai $47^{\circ} \mathrm{C}$ dengan setpoin $45^{\circ} \mathrm{C}$. Untuk mendapatkan hasil yang sama dengan pengeringan tradisional, waktu yang dibutuhkan untuk alat mengeringkan cengkeh adalah \pm 7 jam tanpa henti. Penggunaan algoritma logika fuzzy yang di terapkan pada alat, dapat mempertahankan kondisi suhu normal yang kita inginkan dengan kecepatan motor exhaust fan sesuai dengan menurunan dan kenaikan suhu. Sehingga alat dapat mengeringkan cengkeh secara optimal.
\end{abstract}

Kata kunci: cengkeh, pengering, fuzzy logic.

(C) 2019 Elektron Jurnal Ilmiah

\section{PENDAHULUAN}

Cengkeh (Syzigium aromaticum) adalah tanaman perkebunan yang dapat mencapai tinggi hingga 20 meter. Daun mudanya berwarna merah muda terang, lalu berubah menjadi hijau kekuningan setelah tua dan mengeras. Bagian yang dimanfaatkan dari tanaman cengkeh adalah bunga dan daunnya. Bunga cengkeh berkelompok dari tiga hingga sepuluh tangkai, dimana setiap tangkai berisi rata-rata tiga kuntum bunga. Cengkeh merupakan produk rempah yang digunakan sebagai salah satu bahan baku industri rokok, farmasi, kosmetik dan rempah-rempah bahan makanan. penjemuran alami yang digunakan petani dapat Besarnya permintaan cengkeh dengan demikian sangat digantikan dengan suatu alat proses pengeringan secara ditentukan oleh perkembangan dari industri-industri otomatis, dimana sistem ini dilengkapi dengan tersebut. Saat musim hujan, produksi cengkeh kering pengendali temperatur.

petani mulai menurun. Petani mengalami kesulitan Dalam beberapa hasil pengujian dan beberapa data dalam mengeringkan cengkeh basah hasil panen dan literatur tentang pemngeringan cengkeh dihasilkan mereka. Cengkeh dapat dikeringkan pada musim bahwa kondisi optimum untuk pengeringan cengkeh ini kemarau dengan bantuan matahari selama 4 hingga 5 adalah pada suhu $40^{\circ} \mathrm{C}$ sampai $50^{\circ} \mathrm{C}$. Untuk hasil jika hari dengan rata-rata waktu penjemuran 8 hingga 10 dibandingkan antara pengeringan secara tradisional jam setiap harinya. Sedangkan pada musim hujan, menggunakan matahari dengan menggunakan pengeringan memakan waktu hingga 6 sampai 10 hari pengeringan buatan menunjukan mutu yang berbeda. tergantung intensitas hujan pada pengeringan cengkeh. Secara umum kondisi penampakan hasil keduanya 
sama, yaitu mempunyai warna coklat-hitam, ukuran seragam tidak ada cengkeh yang rusak tidak ada gagang cengkeh dan kadar air dibawah 14\%. Namun kadar minyak atsiri pada pada cengkeh dengan pengeringan buatan lebih tinggi dari pengeringan secara tradisional, karena metode ini cengkeh akan terkena radiasi langsung dari matahari yang menyebabkan suhu cengkeh bisa cukup tinggi yang mengakibatkan penguapan minyak atsiri ${ }^{[7]}$.

Dan alat ini dapat menurunkan kadar air dan perubahan suhu yang terjadi didalam box pengering dapat dipantau dengan pencapaian suhu setpoint yang diinginkan berdasarkan pembacaan dari sensor. Untuk membantu perubahan penurunan dan kenaikan suhu yang terjadi pada tabung pengering maka pada alat ini dipakai motor exhaust fan yang kecepatan putaran motornya berdasarkan perubahan suhu yang terjadi didalam box pengering..

\section{METODE PENELITIAN}

Secara keseluruhan alat ini tersusun atas bagianbagian penting yang saling berhubungan satu sama lain yaitu perangkat keras (hardware) dan perangkat lunak (software) dan dapat dikelompokkan menjadi 3 bagian utama yaitu proses input, pengolahan data, dan ouput. Pengaturan alat secara otomatis dengan menggunaan metoda logika fuzzy. setiap konsekuen pada aturan yang berbentuk IF-Then harus direpresentasikan dengan suatu himpunan fuzzy dengan fungsi keanggotaan yang monoton. Sebagai hasilnya, output hasil inferensi dari tiap-tiap aturan diberikan secara tegas (crips) berdasarkan $\alpha$-predikat (fire strength). Hasil akhirnya diperoleh dengan menggunakan ratarata terbobot. Proses defuzzifikasi dilakukan untuk menghimpun input yang terdiri dari komposisi aturanaturan fuzzy, sedangkan output yang dihasilkan merupakan suatu bilangan pada domain himpunan fuzzy tersebut. Sehingga jika diberikan suatu himpunan fuzzy dalam range tertentu, maka harus dapat diambil suatu nilai crips tertentu sebagai output.

\section{Deffuzifikasi :}

$\mathrm{Zt}=\left(\left(\mathrm{br} 1 *_{\mathrm{z} 1}\right)+(\mathrm{br} 2 * \mathrm{z} 2)+(\mathrm{br} 3 * \mathrm{z} 3)+(\mathrm{br} 4 * \mathrm{z} 4)+(\mathrm{br} 51 * \mathrm{z} 51)\right.$ $+($ br52*z52)+(br6*z6)+(br7*z7)+(br8*z8)+(br9*z9))

$/(b r 1+$ br $2+$ br $3+$ br $4+$ br $5+$ br $5+$ br $6+$ br $7+$ br $8+$ br9)

\subsection{Blok Diagram}

Berikut blok diagram dibawah ini menjelaskan tentang sistem pengering cengkeh secara keseluruhan.

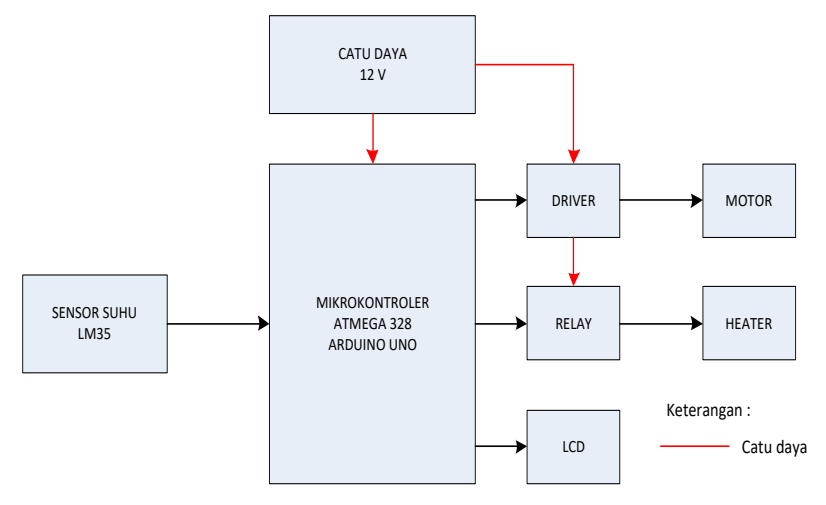

Gambar 1. Blok Diagram Alat Penegring Cengkeh

Fungsi masing-masing blok :

1. Sensor LM35 berfungsi untuk mengukur nilai suhu yang terbaca pada box pengering..

2. Mikrokontroler berfungsi untuk mengolah data input dari sensor LM35.

3. Driver motor berfungsi sebagai saklar untuk menghidupkan motor sesuai dengan nilai logika yang dikirimkan oleh mikrokontroler.

4. Relay berfungsi sebagai saklar untuk menghidupkan dan mematikan heater dengan sistem pengontrolan ON-OFF berdasarkan setpoint suhu.

5. Motor berfungsi untuk menggerakkan fan ruang box pengering.

6. LCD berfungsi untuk menampilkan nilai suhu yang terbaca serta berapa lama waktu yang digunakan untuk sistem pengeringan.

\subsection{Perancangan hardware}

Proses input yang diinginkan dapat diatur melalui setpoint pada mikrokontroler untuk mengaktifkan plant (motor dan heater). Pada saat alat aktif, elemen pemanas (heater) mulai bekerja dan sensor LM35 akan membaca suhu ruang box pengering. Heater akan bekerja pada batas suhu normal dari setpoint dan tidak aktif apabila suhu diatas batas suhu normal yang diberikan. Motor fan akan bekerja apabila suhu naik menjadi $46^{\circ} \mathrm{C}$ yang terbaca oleh sensor suhu LM35. Proses selanjutnya yaitu pengolahan data pada mikrokontroler dari sensor. Nilai ini nantinya berfungsi untuk mengatur kecepatan motor fan dan on-off relay. Kecepatan motor akan diatur berdasarkan metoda fuzzy, dimana kecepatan motor fan merupakan output deffuzikasi pada fuzzy control. Pada saat suhu melebihi batas normal ( $>50^{\circ} \mathrm{C}$ ) maka kecepatan motor fan akan bertambah dan heater akan di nonaktifkan oleh solid state relay. Motor fan akan tetap aktif untuk menurunkan suhu pada box pengering agar suhu ruang pada box kembali normal. Dari tampilan LCD dapat melihat kenaikan dan penurunan suhu yang terbaca oleh sensor. 


\subsection{Perancangan Software}

Perancangan perangkat lunak merupakan perancangan mengenai algoritma pemograman yang akan digunakan pada alat pengering cengkeh ini. Algoritma merupakan garis besar jalannya suatu program. Salah satu bentuk algoritma dituangkan dalam bentuk diagram alir ( flowchart ).

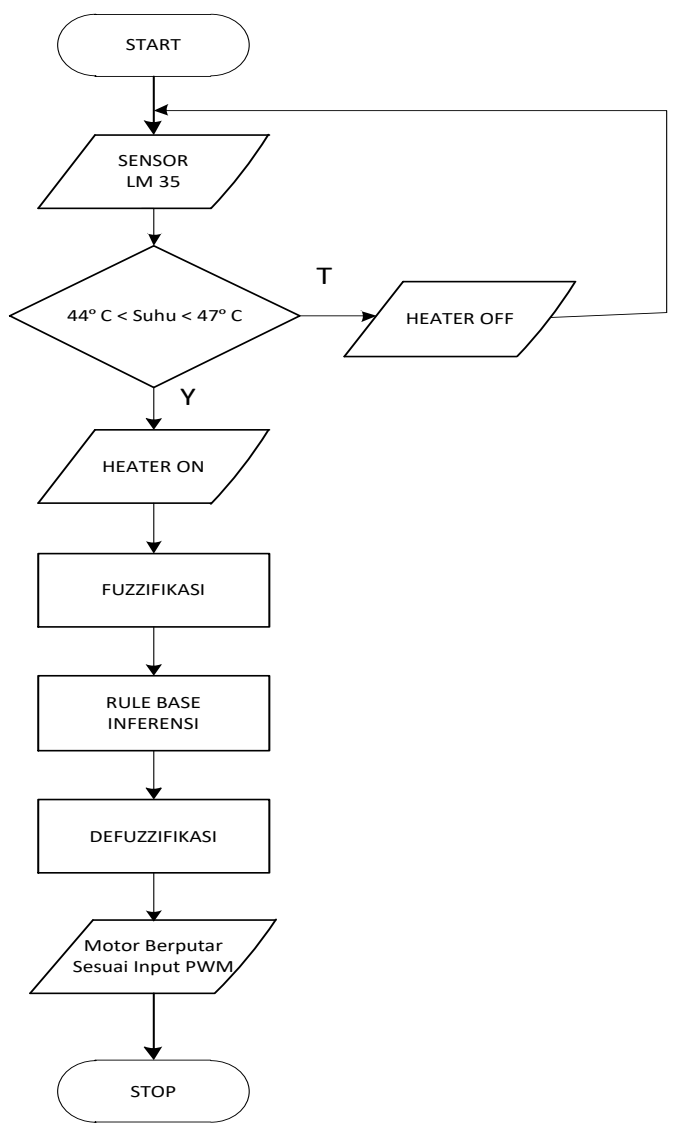

Gambar 2.Flowchart Alat Pengering cengkeh

Flowchart diatas dapat menggambarkan cara kerja alat secara keseluruhan. Dimulai pada tahap awal ( START ) kemudian dilanjutkan dengan pembacaan suhu pada box pengering cengkeh. Apabila suhu terbaca $<45^{\circ} \mathrm{C}$ heater akan aktif (keadaan $\mathrm{ON}$ ). Pada suhu $\geq 45^{\circ} \mathrm{C}$ maka alat akan lanjut bekerja berdasarkan rule Fuzzifikasi yang dibuat. Sehingga kecepatan motor fan akan berputar sesuai dengan data input yang dimasukkan. Heater akan aktif sampai batas setpoint yang ditentukan dan program akan terus beroperasi sesuai dengan kondisi suhu pada data alat percobaan.

\section{HASIL DAN PEMBAHASAN}

Selanjutnya dilakukan pengujian untuk mengetahui apakah sistem yang dibuat telah sesuai dengan yang direncanakan. Selain untuk mengetahui apakah sistem sudah bekerja dengan baik sesuai dengan yang diharapkan.
Pada proses pengeringan yang dilakukan, berat cengkeh yang di timbang adalah 500g. Proses pengeringan dilakukan dengan cara meletakkan cengkeh pada rak pengering yang berada dalam box pengeringan. Heater akan aktif dan menaikan suhu didalam box. Sensor LM35 berada didalam box pengering untuk membaca perubahan suhu. Pengambilan data dilakukan dengan cara menampilkan nilai suhu dan nilai kecepatan motor fan pada serial monitoring Arduino. Sementara untuk hasil pengukuran nantinya kita menampilkan hasil pada sebuah LCD, program serial monitoring Arduino diganti dengan program serial print LCD sehingga data pengukuran data ditampilkan pada LCD.

Untuk perhitungan daya yang dari output yang digunakan pada alat ini adalah:

Tabel 1. Daya Heater yang Digunakan

\begin{tabular}{|c|c|c|c|c|c|}
\hline Nama Komponen & Jumlah & Arus & $\begin{array}{c}\text { Tegangan } \\
\text { Input }\end{array}$ & Daya & $\begin{array}{l}\text { Daya } \\
\text { Total }\end{array}$ \\
\hline $\begin{array}{l}\text { Heater HDE } 09 \\
\text { Persegi Panjang }\end{array}$ & 10 buah & $227 \mathrm{~mA}$ & $220 \mathrm{VAC}$ & 50 Watt & 500 Watt \\
\hline $\begin{array}{c}\text { Heater HDE } 09 \\
\text { Persegi }\end{array}$ & 6 buah & $181 \mathrm{~mA}$ & $220 \mathrm{VAC}$ & 40 Watt & 240 Watt \\
\hline \multicolumn{5}{|c|}{ Daya Total } & 740 Watt \\
\hline
\end{tabular}

Pada alat digunakan 10 buah heater persegi panjang dengan daya 50 watt, dengan begitu total daya yang digunakan untuk seluruh heater persegi panjang adalah 500 watt dan 6 buah heater persegi panjang dengan daya 40 watt, dengan begitu total daya yang digunakan untuk seluruh heater persegi panjang adalah 40 watt. Dari perhitungan daya untuk seluruh output yang digunakan pada alat, didapatkan daya total yaitu : 740 Watt. Untuk mendalami analisa dan membandingkan efek dari penggunaan metoda fuzzy, penulis membuat perbandingan alat saat menggunakan metoda fuzzy dan saat tidak menggunakan metoda fuzzy.

Tabel 2. Hasil pengukuran suhu pada saat 13 menit awal menggunakan metoda fuzzy.

\begin{tabular}{|c|c|c|c|c|}
\hline Menit & Suhu & Data ADC & Keadaan Fan & Keadaan Heater \\
\hline 1 & 28,37 & 283 & Off & On \\
\hline 2 & 29.88 & 292 & Off & On \\
\hline 3 & 31.32 & 312 & Off & On \\
\hline 4 & 33.79 & 335 & Off & On \\
\hline 5 & 34.25 & 341 & Off & On \\
\hline 6 & 35.01 & 349 & Off & On \\
\hline 7 & 36.77 & 365 & Off & On \\
\hline 8 & 37.43 & 372 & Off & On \\
\hline 9 & 38.06 & 379 & Off & On \\
\hline 10 & 39.81 & 396 & Off & On \\
\hline 11 & 40.63 & 403 & Off & On \\
\hline 12 & 43.02 & 428 & Off & On \\
\hline 13 & 44.94 & 446 & Off & On \\
\hline
\end{tabular}

Berdasarkan tabel di atas dapat dilihat bahwa suhu awal pada pengujian adalah $28^{\circ} \mathrm{C}$. Setelah 13 menit 
pengukuran suhu mencapai keadaan $44.94^{\circ} \mathrm{C}$ sudah mendekati suhu yang diinginkan yaitu $45^{\circ} \mathrm{C}$.

Tabel 3. Hasil pengukuran suhu pada alat mencapai keadaan yang inginkan 13 menit tanpa menggunakan metoda fuzzy.

\begin{tabular}{|c|c|c|c|}
\hline Menit & Suhu & Fan & Heater \\
\hline 1 & 26,37 & Off & On \\
\hline 2 & 27.83 & Off & On \\
\hline 3 & 28.32 & Off & On \\
\hline 4 & 29.79 & Off & On \\
\hline 5 & 31.25 & Off & On \\
\hline 6 & 33.20 & Off & On \\
\hline 7 & 35.16 & Off & On \\
\hline 8 & 37.11 & Off & On \\
\hline 9 & 38.58 & Off & On \\
\hline 10 & 40.04 & Off & On \\
\hline 11 & 41.59 & Off & On \\
\hline 12 & 43.46 & Off & On \\
\hline 13 & 44.92 & Off & On \\
\hline
\end{tabular}

Tabel 4. Hasil defuzzyfikasi PWM terhadap suhu

\begin{tabular}{|c|c|c|c|c|c|}
\hline $\begin{array}{c}\text { Menit } \\
(\mathrm{T})\end{array}$ & Suhu & Error Sekarang & Error Sebelumnya (T-1s) & D error & PWM \\
\hline 15 & 43,95 & 1,05 & 1,85 & $-0,80$ & 0 \\
\hline 20 & 44,88 & 0,12 & 1,02 & $-0,9$ & 72,45 \\
\hline 30 & 45,43 & $-0,43$ & 0,23 & $-0,66$ & 121,77 \\
\hline 40 & 45,29 & $-0,29$ & 0,21 & 0,5 & 152,91 \\
\hline 50 & 45,65 & $-0,65$ & $-0,52$ & $-0,13$ & 187,53 \\
\hline 60 & 45,41 & $-0,41$ & $-0,42$ & $-0,01$ & 220,12 \\
\hline 90 & 45,41 & $-0,41$ & $-0,91$ & 0,50 & 130,32 \\
\hline 100 & 45,43 & $-0,43$ & 0,08 & 0,51 & 140,23 \\
\hline 120 & 44,43 & 0,67 & 0,08 & 0,59 & 102,70 \\
\hline 130 & 46,39 & $-1,39$ & $-1,39$ & 0,00 & 242,00 \\
\hline 140 & 45,90 & $-0,90$ & $-1,39$ & 0,49 & 218,00 \\
\hline 150 & 46,88 & $-1,88$ & $-1,88$ & 0,00 & 243,00 \\
\hline 160 & 45,92 & $-0,92$ & $-1,39$ & 0,47 & 205,13 \\
\hline 170 & 45,81 & $-0,81$ & $-1,31$ & 0,5 & 201,13 \\
\hline 180 & 45,77 & $-0,77$ & $-0,80$ & 0,17 & 192,22 \\
\hline
\end{tabular}

Kipas akan hidup apabila suhu $\geq 44^{\circ} \mathrm{C}$ dengan mendapatkan nilai kecepatan motor berdasarkan kenaikan suhu yang terjadi. Kipas (motor exhaust fan)

disini berfungsi untuk menjaga penurunan dan $\mathrm{t}=(\mathrm{br} 1+\mathrm{br} 2+\mathrm{br} 3+\mathrm{br} 4+\mathrm{br} 5+\mathrm{br} 5+\mathrm{br} 6+\mathrm{br} 7+\mathrm{br} 8+\mathrm{br} 9)$; kenaikan suhu yang terjadi agar didapatkan kondisi suhu normal ( $\geq 45^{\circ} \mathrm{C}-\leq 47^{\circ} \mathrm{C}$ ). Selisih perubahan suhu yang terjadi setelah pencapaian set point awal, sesuai dengan pengondisian suhu normal.

Jika dibandingkan antara kedua hasil pengujian baik menggunakan logika fuzzy maupun tanpa logika fuzzy untuk mencapai suhu awal memerlukan waktu yang hampir sama. Akan tetapi untuk mempertahankan suhu yang diinginkan sangat berbeda dan dapat dilihat pada gambar grafik dibawah ini

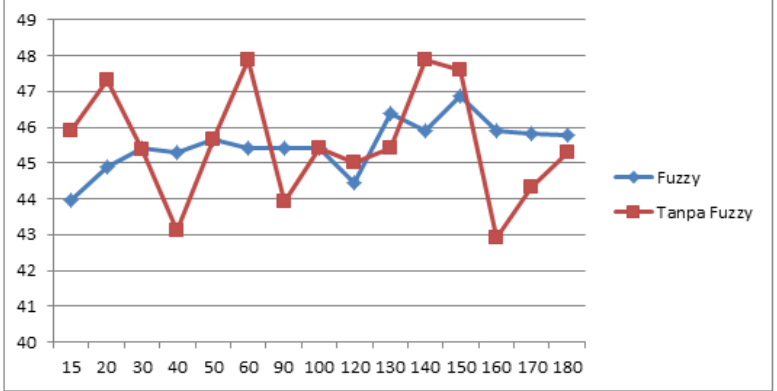

Gambar 2. Grafik Perbandingan Kontrol Suhu dengan dan tanpa metoda logika fuzzy

Dapat dilihat dari grafik perbandingan sangat jelas dalam memperhalus kontrol suhu dalam box dengan waktu yang sama. Hasil pengontrolan menggunakan fuzzy lebih halus (smooth) jika dibandingkan tanpa fuzzy. Dan untuk melakukan pengeringan sendiri waktu yang diperlukan untuk mencapai cengkeh yang kering jika tidak menggunakan logika fuzzy lebih lama \pm 1 jam dibandingkan dengan menggunakan metoda fuzzy.

Untuk hasil cengkeh sendiri antara kedua cara tersebut memiliki bentuk, warna dan aroma yang sama sehingga keuntungan dalam penggunaan metoda fuzzy dalam proses perngeringan sendiri menghasilkan cengkeh kering sedikit lebih cepat dibandingan tanpa menggunakan metoda.

Dari hasil pengukuran dan pencarian nilai terkecil tersebut, dapat dilakukan proses defuzzyfikasi langsung dengan metoda centroid (rata-rata berbobot). Perhitungan crips output dinyatakan dengan rumus :

$\mathrm{z}=$

$(($ br $1 * z 1)+(b r 2 * z 2)+(b r 3 * z 3)+(b r 4 * z 4)+(b r 5 * z 5)+(b r 5$ $\left.\left.*_{\mathrm{z} 6}\right)+(\mathrm{br} 6 * \mathrm{z} 7)+\left(\mathrm{br} 7 *^{\mathrm{z} 8} 8\right)+(\mathrm{br} 8 * \mathrm{z} 9)+(\mathrm{br} 9 * \mathrm{z} 10)\right)$;

$\mathrm{z}=(0.9 * 9)+(0 * 0)+(0 * 0)+(-0.9 * 9)+(-0.9 *-19)+$ $(-0.9 * 19)+(-0.9 *-9)+(0 * 0)+(0 * 0)+(0 * 0)=8,1$ $\mathrm{t}=(0.9)+0+0+(-0.9)+(-0.90)+(-0.90)+(-0.9)+0$ $+0+0=-2,7$

Jadi hasil output yang dihasilkan adalah :

$\mathrm{ZT}=\mathrm{z} / \mathrm{t}=8,1 /-2,7=-3$

$\mathrm{PWM}$ motor $=\mathrm{PWM}$ tadi $+\mathrm{ZT}=220,43+(-3)=217,43$ adalah PWM sekarang.

Jika dibandingkan dengan hasil PWM yang didapatkan dengan hasil yang terbaca pada alat saat menit ke-140 yaitu PWM 217,43, dengan kata lain hasil yang didapatkan sama dengan data PWM yang ditampilkan pada LCD. 


\section{KESIMPULAN}

Setelah dilakukan pergujian dan pengukuran pada alat secara langsung maka dapat diambil kesimpulan :

1. Panas pada box pengering dapat mencapai suhu yang di inginkan setelah 14 menit dan untuk mendapatkan cengkeh kering memerlukan waktu \pm 7 jam.

2. Fuzzy Logic digunakan untuk mengontrol kecepatan fan exhaust.

3. Penggunaan metoda fuzzy logic yang diterapkan pada alat dapat mempertahankan kondisi suhu stabil $\left(\geq 44^{\circ} \mathrm{C}-\leq 47^{\circ} \mathrm{C}\right)$.

4. Kontrol suhu saat menggunakan logika fuzzy lebih baik dari pada tanpa menggunakan fuzzy.

5. Hasil yang didapatkan tanpa menggunakan fuzzy \pm 1 jam lebih lama dibanding menggunakan metoda fuzzy.

\section{REFERENSI}

[1] Datasheet Arduino Uno

[2] Datasheet LM35
[3] Dinas Perkebunan Provinsi Jawa Timur.2013,Budidaya Tanaman Cengkeh,Surabaya:dinas Pertanian

[4] Fitzgerald,A.E.1981."Dasar-Dasar Elektroteknik",Bandung;Erlangga

[5] Karo,Trudly."Spesifikasi Elemen Pemanas Persegi Panjang"20 September 2016 https://www.tokopedia.com/cvttg/elemen-pemanas-tipe-kabelhigh-qualityheater-body-magic-com

[6] Karo,Trudly."Spesifikasi Elemen Pemanas Persegi'20 September 2016. https://www.tokopedia.com/cvttg/elemenpemanas-tipe-kabel-high-qualityheater-penutup-magic-com

[7] Nugroho,W.H.2002."Uji Performansi Alat Pengering Cengkeh Tipe Efek Rumah Kaca,Bogor:Fakultas Pertanian ITB

[8] Nuzband,K.N.2014."Uji Aktifitas Antidepresan Ekstrak Bunga Cengkeh pada Mencit Putih Jantan dengan Metoda Forced Swim Test",Samarinda:Akademi Farmasi Samarinda

[9] Prastyawan,D.2015."Implementasi Mikrokontroler Atmega8I Untuk Pengeringan Cengkeh Pada KUD Ngadirajo, Yogyakarta:STKIP PGRI Pacitan

[10]Tooley,Mike.1995."Rangkaian Elektronik Prinsip dan Aplikasi,'Jakarta:Erlangga 